\title{
Where Does Price Discovery Occur? An Empirical Study of Taiwan's ADRs and Their Underlying Foreign Stocks
}

\author{
Ming-Chieh Wang ${ }^{1} \&$ Yi-Chen $\mathrm{Wu}^{1}$ \\ ${ }^{1}$ Department of International Business Studies, National Chi-Nan University, Taiwan, R.O.C. \\ Correspondence: Ming-Chieh Wang, Department of International Business Studies, National Chi-Nan University, \\ No.1, University Rd., Puli, Nantou 54561, Taiwan, R.O.C. Tel: 886-49-291-0960. E-mail: mcwang@ncnu.edu.tw \\ Received: December 7, 2013 \\ Accepted: May 15, 2014 \\ Online Published: June 1, 2014 \\ doi:10.5430/ijfr.v5n3p43 \\ URL: http://dx.doi.org/10.5430/ijfr.v5n3p43
}

\begin{abstract}
This study analyzes the process of price discovery for five Taiwanese American Depositary Receipts (ADRs) and their underlying foreign stocks. The empirical results reveal three previously undisclosed facts. First, ADRs provide price information during trading periods, and the closing prices of ADRs serve as guidelines for predicting the opening prices of the underlying Taiwan stocks. Second, the market index movements of ADR listing exchanges can explain the returns of ADRs and underlying stocks, but their influence cannot increase if the other index is used. Third, the explanatory power of the U.S. movements does not strengthen during the subprime mortgage financial crisis, despite large changes to the market.
\end{abstract}

Keywords: ADRs, price discovery, cross-listing

\section{Introduction}

In this paper we analyze five Taiwanese firms' American Depositary Receipts (ADRs) on United States (U.S.) stock exchanges to examine where price discovery occurs. Because each ADR can be converted into some multiple of its underlying foreign security, the foreign and U.S. prices of any given security should be the same, according to the law of one price. However, because legal barriers and U.S. and Taiwan stock exchanges trade at non-overlapping times, it is difficult to answer the question of whether ADR trading follows the U.S. market or Taiwan market. Although academic literature has examined price discovery for cross-border listings on U.S. exchanges, empirical results present inconsistencies. Most findings show that ADR prices are more exposed to the home market than the trading market, but a few studies indicate that ADRs have a larger co-movement with the U.S. market. The present study investigates the price information transmission of Taiwan's ADRs and their domestic stocks and interprets the possible reasons for the inconsistent directions in earlier studies.

In studies of cross-listings on U.S. exchanges, Chou et al. (2004) employ vector autoregression, vector error correction, and cross-correlation function methods to examine the price transmission of Taiwan's ADRs. The results show that the underlying stock returns are the most important factor for the ADR returns. Yang et al. (2005) apply the two-stage GJR-GARCH model to investigate the information flows of intra-day returns and volatilities for dual-listing stocks. Using data from Japan, Taiwan, Korea, Hong Kong, and Singapore, they find that the home market is the dominant force, and the price in the U.S. market simply adjusts to the home market price. Gramming et al. (2005) examine the price discovery process of three New York Stock Exchange (NYSE)-listed German stocks between the U.S. and German markets trade at overlapping times; price information originates in the home market. Pascual et al. (2006) show that the Spanish market influences their ADR returns significantly. Su and Chong (2007) also show that the Hong Kong stock exchange dominate the NYSE in influencing the eight Chinese dually-listed stocks.

Agarwal et al. (2007) investigate price discovery of Hong Kong-listed stocks are also traded on the London stock exchange, they indicate that the opening prices of Hong Kong cross-listed stocks in the London exchange approach the closing prices of the underlying Hong Kong stocks, and the stock returns that both trade at the two stock exchanges are highly correlated with the Hong Kong's market movements. They conclude that trading in London is driven primarily by liquidity rather than information. Frijns et al. (2010) examine the dynamics of price discovery for Australian and New Zealand stocks are bilaterally traded on the two markets. They find that in both case the stock returns are driven by their home market sentiment, but the influence of the larger Australia market is increasing for 
these domiciled firms.

Among the few studies that support the notion that ADR prices reflect the price information of U.S. market, Kim et al. (2000) observe that though the price of the underlying stocks is the most important pricing factor, the exchange rate and the U.S. market also affect prices. Iwatsubo and Inagaki (2007) examine the price behavior of ADRs in Asian countries; they find that because the U.S. market is an international financial center, price transmissions flows primarily from the U.S. to Asian markets. He and Yang (2011) find that ADRs returns are priced to the U.S. market rather than their home market by using a regime switching model.

Thus, the price discovery process appears to originate in the home market. In line with Iwatsubo and Inagaki's (2007) result, this study examines whether Taiwan's ADR trading provides relevant price information for underlying stock. The motivation for this study is that the information technology (IT) industries constitute a critical segment of Taiwan's stock market, and Taiwan's IT products are mainly exported to the U.S., especially for hardware capacity such as semiconductor and personal computer manufacturing. Many IT companies (including the five U.S.-listed Taiwanese companies) accept original equipment manufacturer (OEM) orders from large U.S. technology companies, and announcements of such economic statistics or business financial reports in the U.S. affect the Taiwanese stocks' performance on the next trading day. $\mathrm{Ng}$ (2000) and Miyakoshi (2003) also indicate the U.S. market can substantially affect emerging Asian market returns. The core businesses of these ADR-issuing companies are conducted to U.S. market, so their stock prices should closely correspond to this market. Therefore, this market is a good example for examining whether the OEM industry structure can explain ADRs' price discovery.

Because of non-synchronous trading hours, we separate ADR daily returns into overnight and daytime returns and use the weighted price contribution (WPC) method to analyze the effects of U.S. and Taiwan trading on the ADR returns. If the ADRs are driven by the U.S. market, then their closing price will help investors to predict the underlying stock's opening price on the next trading day, and the ADR's day returns will be highly correlated with the overnight returns of the underlying stocks. We use a regression model to analyze the explanatory power of U.S. and Taiwan market movements on the ADR returns. The advantage of this study is its simplicity, which enables individual investors and researchers to understand the resulting models easily. No prior empirical literature has addressed the correlation between the opening and the closing prices of the U.S. and Taiwanese stocks or examined the influence of market index movements on the price of cross-listed stocks. Therefore, this study uses a simple but effective method to explore the price discovery process between the two markets. In addition, because Taiwan's ADRs consist of companies that produce electronics and semiconductors, alternative stock indexes can reveal whether explanatory power is greater in indexes other than those in which ADRs are traded (e.g., NASDAQ [National Association of Securities Dealers Automated Quotation] and SOX [Philadelphia Semiconductor Index]). Finally, this paper examines the dynamics of price discovery during the subprime mortgage financial crisis that originated in the U.S. market.

The empirical results show that the price discovery process of Taiwan's ADRs occurs in the U.S. market. The explanatory power of the U.S. market index does not increase if the index (not the ADR listing exchange) is used, though the index closely correlates with the industry to which the ADRs belong. Recent rapid growth in economic ties between the Chinese and Taiwanese markets has reduced the contributions of ADR trading to the price discovery process, even as the U.S. market experienced large movements during its financial crisis.

The remainder of this paper is organized as follows: Section 2 describes the data and methodology, and Section 3 presents the empirical results. Section 4 provides a brief summary.

\section{Data and Methodology}

\subsection{Data}

The test subjects are five U.S.-listed Taiwanese stocks on the NYSE and NASDAQ exchange. To ensure a sufficient amount of data for research, we account for these firms' longer ADR issuing periods. Table 1 presents the five selected companies; four listed on the NYSE, and one on the NASDAQ exchange. In general, these firms represent blue-chip stocks and industry leaders that are considered experts in IT manufacturing services for OEM products. The Center for Research in Security Prices (CRSP) database provide price data for the ADRs, and the Datastream database provide foreign stock prices, exchange rates, and stock index data. It is necessary to consider the effect of exchange rates, because ADR prices are denominated in U.S. dollars. The sample includes the period from January 1, 2004, to December 31, 2006, and then the period surrounding the U.S. financial crisis, from September 1, 2008, to December 31, 2010. 
Table 1. Taiwanese stocks listed on NYSE/NASDAQ

\begin{tabular}{|c|c|c|c|c|c|c|}
\hline $\begin{array}{l}\text { Issuing company } \\
\text { (U.S. symbol) }\end{array}$ & $\begin{array}{c}\text { U.S. stock } \\
\text { exchange } \\
\text { (listing date) } \\
\end{array}$ & Ratio & $\begin{array}{c}\text { Industry } \\
\text { classification }\end{array}$ & $\begin{array}{l}\text { Major } \\
\text { Product }\end{array}$ & $\begin{array}{l}\text { Market } \\
\text { share } \\
\text { ranking }\end{array}$ & $\begin{array}{l}\text { Market } \\
\text { value } \\
\text { ranking }\end{array}$ \\
\hline $\begin{array}{l}\text { Taiwan } \\
\text { Semiconductor } \\
\text { Manufacturing } \\
\text { (TSM) }\end{array}$ & $\begin{array}{c}\text { NYSE } \\
(14 / 10 / 97)\end{array}$ & 5 & $\begin{array}{c}\text { Technology- } \\
\text { Semiconductor } \\
\text { Integrated Circuits }\end{array}$ & $\begin{array}{l}\text { Integrated } \\
\text { circuits (IC) } \\
\text { foundry }\end{array}$ & 1 & 1 \\
\hline $\begin{array}{l}\text { United } \\
\text { Microelectronics } \\
\text { (UMC) }\end{array}$ & $\begin{array}{c}\text { NYSE } \\
(21 / 09 / 00)\end{array}$ & 10 & $\begin{array}{l}\text { Technology- } \\
\text { Semiconductor } \\
\text { Equipment and } \\
\text { Materials }\end{array}$ & IC foundry & 2 & 20 \\
\hline $\begin{array}{l}\text { Advanced } \\
\text { Semiconductor } \\
\text { Engineering } \\
\text { (ASX) } \\
\end{array}$ & $\begin{array}{c}\text { NYSE } \\
(27 / 09 / 00)\end{array}$ & 5 & $\begin{array}{l}\text { Technology- } \\
\text { Semiconductor } \\
\text { Equipment and } \\
\text { Materials }\end{array}$ & $\begin{array}{l}\text { IC packing } \\
\text { and test }\end{array}$ & 1 & 22 \\
\hline $\begin{array}{l}\text { Siliconware } \\
\text { Precision } \\
\text { Industries (SPIL) }\end{array}$ & $\begin{array}{l}\text { NASDAQ } \\
(07 / 07 / 00)\end{array}$ & 5 & $\begin{array}{l}\text { Technology- } \\
\text { Semiconductor } \\
\text { Equipment and } \\
\text { Materials }\end{array}$ & $\begin{array}{l}\text { IC packing } \\
\text { and test }\end{array}$ & 2 & 38 \\
\hline $\begin{array}{l}\text { AU Optronics } \\
(\text { AUO) }\end{array}$ & $\begin{array}{c}\text { NYSE } \\
(29 / 05 / 02)\end{array}$ & 5 & $\begin{array}{l}\text { Technology- } \\
\text { Computer Peripherals }\end{array}$ & $\begin{array}{l}\text { Thin film } \\
\text { transistor liquid } \\
\text { crystal displays } \\
\text { (TFT-LCD) }\end{array}$ & 3 & 14 \\
\hline
\end{tabular}

Notes: This table presents the summary for Taiwan's firms listed on the NYSE and the NASDAQ exchanges. The ratio means that each ADR presents the number of ordinary underlying shares. The industry classification provided by Yahoo! Finance. The statistics for market share ranking (the major product in the world), market value ranking (the relative market value within Taiwan's stock market), and the percentage of foreign investors' shareholdings are measured in 2006.

\subsection{Methodology}

\subsubsection{Weighted Price Contributions (WPC)}

To investigate whether the ADR's closing price can be used as benchmark for the opening price of the underlying Taiwan stock, the WPC method introduced by Barclay and Warner (1993) estimates the contribution that one market's day trading has on the overnight price change of the other market and vice versa. As the U.S. market timings listed in Figure 1 show, no trading hours overlap between the U.S. and Taiwan stock exchange. Therefore, this method employs daily data to measure the contribution by the trading price changes of ADR (underlying Taiwan stocks) to the overnight changes of underlying stocks (ADRs). Let $R N_{i, t}^{A}$ and $R D_{i, t}^{A}\left(R N_{i, t}\right.$ and $\left.R D_{i, t}\right)$ are the overnight and daytime return of ADR (underlying stock), the WPC formula can be expressed as follows:

$$
\mathrm{WPC}=\sum_{t=1}^{T}\left(\frac{\left|R N_{i, t+1}\right|}{\sum_{t=1}^{T}\left|R N_{i, t+1}\right|}\right) \times\left(\frac{R D_{i, t}^{A}}{R N_{i, t+1}}\right)
$$

In the right-hand side of this equation, the first term is the weighting factor for the sample period, and the second term is the relative contribution of the ADR trading period's price change to the underlying stock's overnight price change for the non-overlapping period. A higher WPC values indicate that U.S. trading has a greater influence on the price discovery. In equations (1), we obtain the contribution of the Taiwan trading on the ADR overnight price change by substituting $R N_{i, t+1}$ and $R D_{i, t}^{A}$ with $R N_{i, t}^{A}$ and $R D_{i, t+1}$, respectively. The price discovery will occur in

Taiwan market if $R D_{i, t}$ (ADR's opening price) can capture $R N_{i, t}^{A}$ (underlying stock's closing prices). 


\begin{tabular}{|c|c|c|c|c|}
\hline Taiwan $(\mathrm{T})$ & \multicolumn{4}{|c|}{ Taiwan $(\mathrm{T}+1)$} \\
\hline & & New York $(\mathrm{T})$ & & \\
\hline $1: 30 \mathrm{am}$ & $9: 30 \mathrm{am}$ & $4: 00 \mathrm{pm}$ & $9: 00 \mathrm{pm}$ & EDT hour \\
TWSE & NYSE & NYSE & TWSE & \\
Close & Open & Close & Open & \\
\hline
\end{tabular}

Figure 1. Trading hours of Taiwan and New York stock exchanges

Taiwan standard time is $13 \mathrm{~h}$ ahead of New York. The trading hours of the Taiwan stock exchange (TWSE) are 9:00 am to 1:30 pm in local time. The trading hours of the NYSE are 9:30 am to 4:00 pm in local time.

\subsubsection{Regression Model}

This study also examines the relationship between the stock returns and the stock market movements. If ADR returns are correlated more with the U.S. market than the home market, indicates the effects of U.S. market sentiment and location of trade influence ADR trading. To examine the impact of market movement on stock returns, we use the following formula:

$$
\begin{gathered}
A D R_{i, t}=\alpha_{0, i}+\alpha_{11, i} R_{m, t}+\alpha_{12, i} R_{m, t+1}+\alpha_{2, i} R_{m, t}^{U S}+\alpha_{3, i} E X_{t}+\varepsilon_{i, t}, \\
R_{i, t+1}=\beta_{0, i}+\beta_{1, i} R_{m, t+1}+\beta_{21, i} R_{m, t}^{U S}+\beta_{22, i} R_{m, t+1}^{U S}+\beta_{3, i} E X_{t}+\eta_{i, t+1},
\end{gathered}
$$

where $A D R_{i, t}$ and $R_{i, t}$ represent the returns of the ADR and underlying stock $i$ at time $t$, respectively; $R_{m, t}$ and $R_{m, t}^{U S}$ represent the stock index returns for the index in which the foreign stocks and ADRs are traded, respectively; $E X_{t}$ denotes the exchange rate movement. Agarwal et al. (2007) find that the trading hours for ADRs do not synchronize with the underlying market. Therefore, inserting the periods associated with foreign and U.S. market returns $\left(R_{m, t+1}\right.$ and $\left.R_{m, t+1}^{U S}\right)$ into equations (2) and (3), respectively, may assign an unfair weight to the foreign market returns. To determine whether the high-correlation phenomenon occurred between any two variables, we use Pearson's correlations test to examine the relationships. The data show no high correlations in the regression variables.

\section{Empirical Results}

\subsection{Weighted Price Contribution (WPC) Results}

This study examines the effect of ADR (underlying stock) trading on the price discovery of the underlying stock (ADR) in Taiwan's market. Table 2 presents the WPC values. This table shows that for the Taiwanese market, the overall average values of the two market comparisons indicate that the opening price of underlying Taiwan stocks will incorporate the information of ADR price change during trading periods. The $85.38 \%$ explanatory value (i.e., level at which U.S. daytime returns affect Taiwan's overnight returns) is substantially greater than the $65.64 \%$ explanatory value for Taiwan's daytime trading on U.S. overnight returns. Accordingly, the closing prices of U.S.-listed Taiwanese stocks predict the opening prices on the following trading day. 
Table 2. ADRs (underlying stocks) daytime returns vs. underlying stocks (ADRs) overnight returns

\begin{tabular}{lcc}
\hline Company & U.S. daytime vs. Taiwan overnight (\%) & Taiwan daytime vs. U.S. overnight (\%) \\
\hline TSM & 92.04 & $\mathbf{4 9 . 6 7}$ \\
UMC & 102.03 & 55.82 \\
ASX & 65.47 & 79.34 \\
SPIL & 85.28 & 67.99 \\
AUO & 82.15 & 75.39 \\
\hline Overall average & 85.38 & 65.64 \\
\hline
\end{tabular}

Notes: Table 2 summarizes WPC results for the contribution of U.S. (Taiwan) trading return on Taiwan (U.S.) overnight return as measured by equation (1). The average is also reported in this table.

The WPC results show that Taiwan's ADRs provide price information. In particular, the companies TSM and UMC have the greatest WPC values for U.S. day trading, possibly because their products related to U.S. economic activity. That is, TSM and UMC are the largest and second-largest dedicated semiconductor foundries, best known for their logic chip products. Several U.S. high-tech companies are main OEM customers. Therefore, U.S. consumer spending directly affects the operational revenues of TSM and UMC, the greater WPC values indicate that the U.S. price information informs investors that they should set the opening prices of these companies, and their price information originates from the market in which ADRs are traded. (Note 1)

The WPC results indicate inconsistent directions in price information flows. This mixed empirical evidence seems to align with the conclusions of non-overlapping results provided by Agarwal et al. (2007) or Iwatsubo and Inagaki (2007). The Taiwan's ADR-issuing companies mainly constitute original equipment manufacturers for U.S. companies. Trading of ADRs provides the relevant price information and the U.S. price thus affects their stock prices.

\subsection{Regression Results for the Stock Returns and stock Market Movements}

\subsubsection{The Effect of Using NYSE or NASDAQ as the U.S. Market Index}

We next investigate the relationship between stock returns and stock market movements to determine which market dominates price information. The NYSE or NASDAQ index (depending on the ADR listing market) and the TAIEX (Taiwan Stock Exchange Capitalization Weighted Stock Index) represent U.S. and Taiwanese stock markets, respectively. Table 3 reports the results of equations (2) and (3). Panel A indicates that all five companies have statistically significant $\alpha_{11}$ (5\% level) and that three companies (cf. UMC and SPIL) have significant but lower estimated values of $\alpha_{12}$. The coefficients of $\alpha_{2}$ are also significant, and the exchange rate does not affect the ADR returns. Therefore, ADR returns are driven both by the home and the trading market risks. Comparing the coefficients shows that U.S. market movement is the most important factor on ADR returns. The aggregate influence of the Taiwanese market movements $\left(\alpha_{11}+\alpha_{12}\right)$ reveals that only ASX is greater than $\alpha_{2}$. Thus, the trading of ADRs has the capability to support price discovery and is not driven purely by liquidity.

Panel B of Table 3 presents the results of equation (3). Home market movement ( $\left.\beta_{1}\right)$ best explains the returns of the underlying stock. However, the change in the U.S. market from the previous day $\left(\beta_{21}\right)$ also has an impact on these companies (cf. AUO). The regression results show that U.S. market index returns enhance the explanatory power of Taiwan's ADRs and underlying stocks, consistent with the WPC results. 
Table 3. Regression results

\begin{tabular}{|c|c|c|c|c|c|}
\hline \multicolumn{6}{|c|}{ Panel A: ADR returns } \\
\hline Company & $\alpha_{0}\left(\times 10^{-3}\right)$ & $\alpha_{11}$ & $\alpha_{12}$ & $\alpha_{2}$ & $\alpha_{3}$ \\
\hline \multirow{2}{*}{ TSM } & -0.6 & $0.66 * * *$ & $0.13 * * *$ & $1.41^{* * *}$ & 0.42 \\
\hline & $(-0.13)$ & $(12.42)$ & $(2.86)$ & $(14.35)$ & $(1.82)$ \\
\hline \multirow{2}{*}{ UMC } & -1.1 & $0.76^{* * *}$ & 0.08 & $1.63 * * *$ & 0.55 \\
\hline & $(-1.67)$ & $(12.15)$ & $(1.51)$ & (13.92) & (1.73) \\
\hline \multirow{2}{*}{ ASX } & -0.5 & $1.09 * * *$ & $0.17 * *$ & $0.99 * * *$ & 0.44 \\
\hline & $(-0.66)$ & $(15.23)$ & $(2.19)$ & $(7.19)$ & $(1.60)$ \\
\hline \multirow{2}{*}{ SPIL } & 0.4 & $0.90 * * *$ & 0.03 & $1.20 * * *$ & -0.12 \\
\hline & $(0.55)$ & $(10.12)$ & $(0.43)$ & $(11.02)$ & $(-0.73)$ \\
\hline \multirow{2}{*}{ AUO } & -0.4 & $1.05 * * *$ & $0.19 * *$ & $1.42 * * *$ & $-0.52 *$ \\
\hline & $(-0.48)$ & $(11.65)$ & $(1.98)$ & $(9.19)$ & $(-2.14)$ \\
\hline
\end{tabular}

Panel B: Underlying stocks

\begin{tabular}{lcllcc}
\hline Company & $\beta_{0}\left(\times 10^{-3}\right)$ & $\beta_{1}$ & $\beta_{21}$ & $\beta_{22}$ & $\beta_{3}$ \\
\hline \multirow{2}{*}{ TSM } & 0.2 & $1.18^{* * *}$ & $0.41^{* * *}$ & -0.08 & 0.09 \\
& $(0.54)$ & $(25.28)$ & $(5.08)$ & $(-1.07)$ & $(0.64)$ \\
\hline \multirow{2}{*}{ UMC } & -0.7 & $1.22 * * *$ & $0.27 * * *$ & 0.09 & $0.37 * *$ \\
& $(-1.41)$ & $(20.97)$ & $(3.35)$ & $(1.37)$ & $(2.34)$ \\
\hline \multirow{2}{*}{ ASX } & -0.4 & $1.41 * * *$ & $0.38^{* * *}$ & -0.12 & $0.36^{* *}$ \\
& $(-0.53)$ & $(18.68)$ & $(3.60)$ & $(-0.89)$ & $(2.14)$ \\
\hline \multirow{2}{*}{ SPIL } & -0.1 & $1.32^{* * *}$ & $0.24 * *$ & -0.06 & 0.07 \\
& $(-0.05)$ & $(14.94)$ & $(2.28)$ & $(-0.57)$ & $(0.61)$ \\
\hline \multirow{2}{*}{ AUO } & -0.5 & $1.44 * * *$ & -0.09 & 0.01 & $0.42 *$ \\
& $(-0.75)$ & $(17.13)$ & $(-0.84)$ & $(0.13)$ & $(1.91)$ \\
\hline
\end{tabular}

Notes: Panel A summarizes equation (2) results which show that the influence of the Taiwan and U.S. market index returns (NYSE or NASDAQ, depending on the ADRs listing market) on the ADR returns of Taiwan's ADRs. Panel B represents equation (3) results for the underlying stocks. The $t$-statistics are included in the parentheses. The robust $\mathrm{t}$ statistics are calculated using Newey and West's (1987) heteroskedasticity and autocorrelation consistent variance-covariance matrix. Denotes $* * *$ significant at the $1 \%$ level, $* *$ significant at the $5 \%$ level, and $*$ significant at the $10 \%$ level.

The overall results contrast with Agarwal et al.'s (2007) findings, which suggest that the prices of Hong Kong's stock cross-listings in London follow movements in the home market more closely than those in the trading market. The empirical evidence in this study indicates that returns in the U.S. market index have more explanatory power over most ADR returns. Thus, the finding show that Taiwan's ADR-issuing companies have substantial U.S. operation sources; their ADR returns are driven by the price information of underlying market and trading market. In addition, though the underlying stock returns depended on the home market, the U.S. market movement is statistically significant in explaining their returns.

The empirical results provide the expected evidence that ADR prices are largely determined in the U.S. market, not the home market. The economic relationship between the two markets plays an important role in price transmission. Trading of ADRs shows investors' expectations regarding the home market performance on the next trading day, and 
ADRs' closing prices can be used as a guideline to forecast the prices of their underlying stocks.

\subsubsection{The Effect of Using NASDAQ or SOX as the U.S. Market Index}

The empirical results indicate that Taiwan's ADRs have the price discovery ability and that U.S. movements (NYSE or NASDAQ) affect their underlying stocks. However, it is also important to investigate whether any other market index is worth adopting as well. Taiwanese cross-listed U.S. stocks involve in the technology industry, and the NASDAQ is the largest U.S. electronic screen-based stock index, popular among foreign investors. Therefore, this paper replaces the NYSE with the NASDAQ for the four NYSE-listed stocks (TSM, UMC, ASX, and AUO) in Eqs. (2) and (3) to investigate NASDAQ's explanatory power for these high-technology companies.

In addition, the SOX index comprises 19 companies primarily involve in the design, manufacturing, and sale of semiconductors. The four Taiwanese companies (TSM, UMC, ASX, and SPIL) also can be classified in the semiconductor industry, and TSM is one of the components listed in SOX. Therefore, we replace the indexes with SOX for the trading exchanges of their ADRs in the regression model, and examine whether the two correlated market indexes have a greater impact on Taiwanese ADRs and their underlying stocks.

According to the empirical results in Table 4, replacing the NYSE with the NASDAQ (Panel A) reveals the coefficient value $\alpha_{2}$ lower than that in Table 3 . These findings show that the NASDAQ affects the returns of Taiwanese ADRs less than the NYSE, even though the companies belong to the technology industry. Regarding the effect on the underlying stocks, the explanatory ability of the TAIEX decrease, because of the lower $\beta_{1}$ values, and the NASDAQ offers slightly more explanatory power for TSM $\left(\beta_{21}\right)$ and $\operatorname{UMC}\left(\beta_{22}\right)$. Overall though, the differences are minimal. Although the NASDAQ is an indicator of the U.S. technology industry and a well-known index for Taiwanese investors, its influence does not exceed that of the NYSE.

Similarly, in Panel B of Table 4, the result of SOX index reveals the coefficients values of $\alpha_{11}$ and $\alpha_{2}$ are statistically significant, but the values are lower than the coefficients in Panel A of Table 3. Thus, SOX offers no advantage over the NYSE when used in the regression model. In terms of the underlying stock returns, the sums of the coefficients $\beta_{21}$ and $\beta_{22}$ are not higher than their corresponding values in Panel $\mathrm{B}$ of Table 4. The decreasing value of the coefficients implies that SOX has less power for explaining these returns. The TAIEX index movement also influences these underlying stock returns significantly. The regression results prove that the market index returns of both the home market and the U.S. market exert significant influences on Taiwan's ADRs. Notably, the insertion of any $\mathrm{m}$ arket index into the regression equation results in a significantly similar outcome. The values of coefficient $\alpha_{2}$ differ though. A comparison of the three U.S. indexes shows that NYSE is higher than NASDAQ, which in turn is higher than SOX. Regarding the factors affecting the underlying stock returns, the TAIEX offers the highest explanatory ability. Although TSM is one of the component stocks included in SOX, SOX still does not exert a greater influence. This influence pertains to both ADRs and Taiwan's underlying stocks. 
Table 4. Regression results of the stock returns on the returns of U.S. stock index (NASDAQ or SOX) and Taiwan stock index

\begin{tabular}{|c|c|c|c|c|c|c|c|c|}
\hline \multicolumn{2}{|c|}{ Dependent variable } & \multicolumn{2}{|c|}{ ADR returns } & \multicolumn{5}{|c|}{ Underlying stock returns } \\
\hline Company & $\mathrm{y} \quad \alpha_{11}$ & $\alpha_{12}$ & $\alpha_{2}$ & $\alpha_{3}$ & $\beta_{1}$ & $\beta_{21}$ & $\beta_{22}$ & $\beta_{3}$ \\
\hline TSM & $\begin{array}{c}0.61^{* * *} \\
(13.38)\end{array}$ & $\begin{array}{l}0.07 * * \\
(1.88)\end{array}$ & $\begin{array}{l}1.24 * * * \\
(18.27)\end{array}$ & $\begin{array}{c}-0.09 \\
(-0.69)\end{array}$ & $\begin{array}{l}1.14^{* * *} \\
(24.95)\end{array}$ & $\begin{array}{l}0.41 * * * \\
(7.38)\end{array}$ & $\begin{array}{c}0.01 \\
(0.03)\end{array}$ & $\begin{array}{l}0.073 \\
(0.50)\end{array}$ \\
\hline UMC & $\begin{array}{c}0.71^{* * *} \\
(12.51)\end{array}$ & $\begin{array}{c}0.05 \\
(0.88)\end{array}$ & $\begin{array}{l}1.32 * * * \\
(16.10)\end{array}$ & $\begin{array}{r}0.36 \\
(1.62)\end{array}$ & $\begin{array}{l}1.18^{* * *} \\
(21.00)\end{array}$ & $\begin{array}{l}0.25 * * * \\
(4.86)\end{array}$ & $\begin{array}{l}0.13 * * \\
(2.54)\end{array}$ & $\begin{array}{c}0.08 \\
(0.55)\end{array}$ \\
\hline ASX & $\begin{array}{c}1.07 * * * \\
(13.89)\end{array}$ & $\begin{array}{l}0.15^{* *} \\
(2.05)\end{array}$ & $\begin{array}{c}0.81 * * * \\
(8.78)\end{array}$ & $\begin{array}{r}0.44 \\
(1.60)\end{array}$ & $\begin{array}{l}1.38^{* * *} \\
(18.45)\end{array}$ & $\begin{array}{l}0.34 * * * \\
(4.37)\end{array}$ & $\begin{array}{c}-0.09 \\
(-1.02)\end{array}$ & $\begin{array}{l}0.47 * * \\
(2.11)\end{array}$ \\
\hline AUO & $\begin{array}{c}1.03 * * * \\
(11.77)\end{array}$ & $\begin{array}{c}0.17^{*} \\
(1.77)\end{array}$ & $\begin{array}{c}1.10^{* * *} \\
(8.69)\end{array}$ & $\begin{array}{l}-0.49 * \\
(-1.94)\end{array}$ & $\begin{array}{l}1.41 * * * \\
(17.77)\end{array}$ & $\begin{array}{l}-0.03 \\
(-0.38)\end{array}$ & $\begin{array}{r}-0.08 \\
(-1.14)\end{array}$ & $\begin{array}{c}0.42 * \\
(1.80)\end{array}$ \\
\hline
\end{tabular}

Panel B: SOX index

\begin{tabular}{ccccccccc}
\hline \multirow{2}{*}{ TSM } & $0.56^{* * *}$ & $0.10^{* * *}$ & $0.74 * * *$ & -0.16 & $1.14^{* * *}$ & $0.27 * * *$ & 0.02 & 0.14 \\
& $(12.42)$ & $(2.62)$ & $(20.34)$ & $(-1.08)$ & $(28.75)$ & $(9.72)$ & $(0.84)$ & $(1.13)$ \\
\hline \multirow{2}{*}{ UMC } & $0.70^{* * *}$ & $0.11^{* *}$ & $0.73^{* * *}$ & 0.20 & $1.19^{* * *}$ & $0.17^{* * *}$ & $0.06 * *$ & 0.12 \\
& $(11.80)$ & $(2.17)$ & $(17.88)$ & $(0.99)$ & $(22.85)$ & $(5.44)$ & $(2.19)$ & $(0.87)$ \\
\hline \multirow{2}{*}{ ASX } & $1.06^{* * *}$ & $0.19^{* *}$ & $0.45^{* * *}$ & 0.21 & $1.40^{* * *}$ & $0.22^{* * *}$ & -0.02 & $0.47 * *$ \\
& $(14.88)$ & $(2.38)$ & $(9.32)$ & $(0.78)$ & $(20.12)$ & $(4.91)$ & $(-0.57)$ & $(2.23)$ \\
\hline \multirow{2}{*}{ SPIL } & $0.88^{* * *}$ & 0.08 & $0.66^{* * *}$ & 0.19 & $1.30^{* * *}$ & $0.21^{* * *}$ & 0.01 & 0.04 \\
& $(9.78)$ & $(1.26)$ & $(11.21)$ & $(0.63)$ & $(16.26)$ & $(4.12)$ & $(0.18)$ & $(0.24)$
\end{tabular}

Notes: Panel A summarizes equations (2) and (3) results which show that the influence of the Taiwan and U.S. market index (NASDAQ) returns on the ADR and underlying stock returns. Panel B represents equations (2) and (3) results for the SOX index. The $t$-statistics are included in the parentheses. The robust $\mathrm{t}$ statistics are calculated using Newey and West's (1987) heteroskedasticity and autocorrelation consistent variance-covariance matrix. Denotes *** significant at the $1 \%$ level, $* *$ significant at the $5 \%$ level, and * significant at the $10 \%$ level.

\subsubsection{Re-examining the Price Discovery Process during the Financial Crisis}

In late 2008, the rapid collapse of the mortgage-backed securities market in the U.S. spread to global financial markets. Equity markets dropped worldwide, the DJIA showed the worst annual performance since the early 1930s, and capital fled many promising emerging markets. During the financial crisis, which began in September 2008 and extended though January 2009, foreign institutional investors holding Taiwan's equities declined, which caused the value of TAIEX to plunge by more than $33 \%$. These evidences clearly show that the U.S. market contributes more to the price discovery process of the five Taiwanese U.S.-listed stocks. However, the results should be carefully re-examined to consider the increasing impact of China on the Taiwanese economy. Taiwan is heavily dependent on China for sourcing of many IT products, (Note 2) and China's GDP has continued to increase during this period. At the end of 2010, the Shanghai Stock Exchange (SSE) composite index rose by 50\% more than that in September 2008 , and the TAIEX rose $30 \%$ in this period, but the performance of DJIA is limited. From September 1, 2008, to 
December 31, 2010, this extreme movement in the stock markets provides an opportunity to investigate whether the contributions of ADR trading also increase. Therefore, this study uses the WPC and regression models from Section 2 to explain the dynamics of U.S. influence on the Taiwanese market with greater precision.

According to the results in Table 5, the price contributions range from $7.14 \%$ to $63.70 \%$ for ADRs' day trading to explain the overnight returns of their underlying stocks in this period. The average WPC is $35.29 \%$. In contrast, trading in the underlying stocks contributes to $23.07 \%-55.08 \%$ of the overnight price changes in their corresponding ADRs, and the average is $35.19 \%$. The results indicate that the day trading of ADRs does not provide higher WPC values than that of the underlying stocks. In comparison with the results in Panel A of Table 2, all companies show an apparent decrease in the impact of U.S. trading. For example, for TSM and UMC, the WPC of the ADRs remains higher than that of the underlying stocks, but their contribution is reduced from $92 \%$ to $44 \%$ and from $102 \%$ to $63 \%$, respectively. Therefore, despite the large movement that occurred in the U.S. market, the contribution of ADR trading on the price discovery decline, which reflects the influence of the Chinese economy on Taiwan's market during this period.

Table 5. WPC results for Taiwan's ADRs and underlying stocks during the subprime mortgage financial crisis

\begin{tabular}{ccc}
\hline Company Name & U.S. daytime vs. Taiwan overnight (\%) & Taiwan daytime vs. U.S. overnight (\%) \\
\hline TSM & 44.68 & 31.86 \\
UMC & 63.70 & 23.07 \\
ASX & 32.62 & 25.53 \\
SPIL & 7.14 & 55.08 \\
AUO & 28.31 & 40.42 \\
\hline Overall average & 35.29 & 35.19 \\
\hline
\end{tabular}

Notes: Table 6 summaries WPC results for the contribution of the U.S. (Taiwan) trading return on the Taiwan (U.S.) overnight return as measured by equation (1). The sample period is from September 1, 2008, to December 31, 2010.

Finally, this study has employed regression analysis to examine the change in the beta risk for U.S. market movements; the results appear in Table 6. The U.S. market Stock returns are less correlated with the stock returns, compared with the results in Panel A and B of Table 3. Panel A finds that the U.S. movements have a significant influence on the returns of the ADRs, but the coefficients for the influence of U.S. market are lower (cf. SPIL). The average beta $\left(\alpha_{2}\right)$ decreased from 1.33 to 0.83 . Panel B shows a similar trend for the underlying stocks. The magnitude of the effect of U.S. market movements decrease; only two firms (TSM and UMC) have significant but lower coefficient $\beta_{21}$ than those in Table 3. Therefore, this finding is consistent with the notion that the U.S. influence has recently decreased, even when the financial crisis occurs in the U.S. 
Table 6. Regression results during the financial crisis

\begin{tabular}{|c|c|c|c|c|c|}
\hline \multicolumn{6}{|c|}{ Panel A: ADR returns } \\
\hline Company & $\alpha_{0}\left(\times 10^{-3}\right)$ & $\alpha_{11}$ & $\alpha_{12}$ & $\alpha_{2}$ & $\alpha_{3}$ \\
\hline \multirow{2}{*}{ TSM } & 0.5 & $0.24 * *$ & 0.16 & $0.57 * * *$ & -0.05 \\
\hline & $(0.78)$ & $(2.23)$ & $(0.12)$ & $(8.79)$ & $(0.87)$ \\
\hline \multirow{2}{*}{$\mathrm{UMC}$} & 0.3 & 0.16 & 0.11 & $1.11^{* * *}$ & 0.69 \\
\hline & $(0.31)$ & $(0.33)$ & $(0.55)$ & $(11.39)$ & $(0.28)$ \\
\hline \multirow{2}{*}{ ASX } & 1.7 & $0.33 * *$ & 0.16 & $0.50 * * *$ & -0.55 \\
\hline & $(0.45)$ & $(2.45)$ & $(0.26)$ & $(22.45)$ & $(0.28)$ \\
\hline \multirow{2}{*}{ SPIL } & 0.1 & $0.51 * * *$ & 0.09 & $1.37 * * *$ & -0.17 \\
\hline & $(0.94)$ & $(22.45)$ & $(0.36)$ & (17.69) & $(0.66)$ \\
\hline \multirow{2}{*}{ AUO } & 0.1 & $0.52 * * *$ & -0.03 & $0.59^{*}$ & 0.31 \\
\hline & $(0.98)$ & $(16.88)$ & $(0.82)$ & $(12.45)$ & $(0.49)$ \\
\hline \multicolumn{6}{|c|}{ Panel B: Underlying stocks } \\
\hline Company & $\beta_{0}\left(\times 10^{-3}\right)$ & $\beta_{1}$ & $\beta_{21}$ & $\beta_{22}$ & $\beta_{3}$ \\
\hline \multirow{2}{*}{ TSM } & -0.6 & $1.01 * * *$ & $0.09 * * *$ & $0.07 *$ & -0.02 \\
\hline & $(0.56)$ & $(8.91)$ & $(2.97)$ & $(1.86)$ & $(0.91)$ \\
\hline \multirow{2}{*}{ UMC } & 0.4 & $1.16^{* * *}$ & $0.17 * * *$ & 0.01 & 0.19 \\
\hline & $(0.77)$ & (18.94) & $(9.71)$ & $(0.86)$ & $(0.48)$ \\
\hline \multirow{2}{*}{ ASX } & -0.8 & $1.02 * * *$ & -0.02 & 0.03 & -0.22 \\
\hline & $(0.73)$ & (12.74) & $(0.79)$ & $(0.70)$ & $(0.63)$ \\
\hline \multirow{2}{*}{ SPIL } & -0.5 & $1.15^{* * *}$ & 0.03 & $0.13 * *$ & -0.24 \\
\hline & $(0.65)$ & $(16.74)$ & $(0.56)$ & $(2.87)$ & $(0.32)$ \\
\hline \multirow{2}{*}{ AUO } & -1.3 & $1.19^{* * *}$ & 0.05 & 0.012 & $0.59 * *$ \\
\hline & $(0.24)$ & $(9.86)$ & $(0.25)$ & $(0.68)$ & (2.17) \\
\hline
\end{tabular}

Notes: Panel A summarizes Eq. (2) results which show that the influence of the Taiwan and U.S. market index returns (NYSE or NASDAQ, depending on the ADRs listing market) on the returns of Taiwan's ADRs during the period from September 1, 2008, to December 31, 2010. Panel B summarizes equation (3) results for the underlying stocks. The $t$-statistics are included in the parentheses. The robust $\mathrm{t}$ statistics are calculated using Newey and West's (1987) heteroskedasticity and autocorrelation consistent variance -covariance matrix. Denotes *** significant at the $1 \%$ level, ** significant at the $5 \%$ level, and * significant at the $10 \%$ level.

\section{Conclusions}

Because they are easily acquired and provide cost savings in foreign investments, ADRs represent an important financial product for investors. This study has investigated the markets that affect the returns of Taiwanese companies and their cross-listing stocks on U.S. exchanges. The findings provide investors with a way to predict the opening prices of their investments. The empirical results show that the trading of ADRs has explanatory power in determining underlying stock prices, and the underlying stocks prices follow their ADR prices. These results contradict much of the findings in previous research, largely due to the specific structure of Taiwan's IT industry. However, this study also reveals that the influence of U.S. market movements has decreased primarily due to the economic linkage between China and Taiwan, a link that strengthened during the financial crisis. These conclusions should help investors forecast stock price movements more accurately. 


\section{References}

Agarwal, S. Liu, C., \& Rhee, S. G. (2007). Where does price discovery occur for stocks traded in multiple markets? Evidence from Hong Kong and London. Journal of International Money and Finance, 26, 46-63. http://dx.doi.org/10.1016/j.jimonfin.2006.10.011

Cao, C. Ghysels, E., \& Hatheway, F. (2000). Price discovery without trading: evidence from the Nasdaq Reopening. Journal of Finance, 55, 1339-1365. http://dx.doi.org/10.1111/0022-1082.00249

Chou, R. K. Hsu, C. C., \& Wu, C. S. (2004). Return and volatility transmissions between ADRs and the underlying factors. Sun Yat-Sen Management Review, 12, 37-62.

Eun, S. C., \& Sabherwal, S. (2003). Cross-border listings and price discovery: evidence from U.S.-listed Canadian stocks. Journal of Finance, 58, 549-575. http://dx.doi.org/10.1111/1540-6261.00537

Frijn, B. Grilbert, A., \& Tourani-Rad, A. (2010). The dynamics of price discovery for cross-listed shares: evidence from Australia and New Zealand. Journal of Banking and Finance, 34, 498-508. http://dx.doi.org/10.1016/j.jbankfin.2009.08.014

Grammig, J.. Melvin, M., \& Schlag, C. (2005). Internationally cross-listed stock prices during overlapping trading hours: price discovery and exchange rate effects. Journal of Empirical Finance, 12, 139-164. http://dx.doi.org/10.1016/j.jempfin.2003.10.004

He, H., \& Yang, J. (2011). Regime switching analysis of ADR home market pass-through. Journal of Banking and Finance, 35, 204-214. http://dx.doi.org/10.1016/j.jbankfin.2010.07.031

Iwatsubo, K., \& Inagaki. K. (2007). Measuring financial market contagion using dually-traded stocks of Asian firms. Journal of Asian Economics, 18, 217-236. http://dx.doi.org/10.1016/j.asieco.2006.12.009

Kim, M. Szakmary, A. C., \& Mathur, I. (2000). Price transmission dynamics between ADRs and their underlying foreign securities. Journal of Banking and Finance, 24, 1359-1382. http://dx.doi.org/10.1016/S0378-4266(99)00076-X

Miyakoshi, T. (2003). Spillovers of stock return volatility to Asian equity markets from Japan and the U.S. International Financial Markets, Institutions and Money, 13, 383-399. http://dx.doi.org/10.1016/S1042-4431(03)00015-5

Newey, W. K., \& West K. D. (1987). A simple positive semi-definite heteroskedasticity and autocorrelation consistent covariance matrix. Econometrica, 55, 703-708.

$\mathrm{Ng}$, A. (2000). Volatility spillover effects from Japan and the U.S. to the Pacific-Basin. Journal of International Money and Finance, 19, 207-233. http://dx.doi.org/10.1016/S0261-5606(00)00006-1

Pascual, R. Pascual-Fuster, B., \& Climent, F. (2006). Cross-listing, price discovery and the informativeness of the trading process. Journal of Financial Markets, 9, 144-161. http://dx.doi.org/10.1016/j.finmar.2006.01.002

Su, Q., \& Chong, T. (2007). Determining the contributions to price discovery for Chinese cross-listed stocks. Pacific-Basin Finance Journal, 15, 140-153. http://dx.doi.org/10.1016/j.pacfin.2006.07.002

Yang, S. Y. Doong, S. C. Wang, A. T., \& Chang, T. L. (2005). Return and volatility intra-day transmission of dually-traded stocks: The cases of Taiwan, Korea, Hong Kong, and Singapore. Journal of Economics and Management, 1, 119-141.

\section{Notes}

Note 1 . More than $50 \%$ of the two companies' revenues come from U.S. in 2007 . However, this study cannot use the revenue's ratio as the factor for pricing ADR. Because it is difficult to measure the ratio of actual U.S. sales to total sales for Asian IT companies, many companies sell the semi-finished products to other Asian countries, and then resell the finished products to the U.S.

Note 2. China has become Taiwan's largest export partner. In 2003, China and U.S. accounted for $15 \%$ and $17 \%$ of Taiwan's exports, respectively, but those shares reversed to $25 \%$ and $12 \%$ in 2010 . 